Article

\title{
From Point Cloud Data to Building Information Modelling: An Automatic Parametric Workflow for Heritage
}

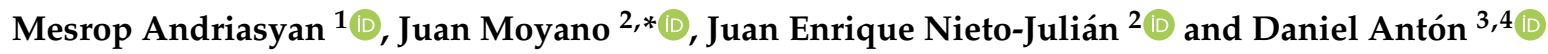 \\ 1 Department of Architecture, Built Environment, and Construction Engineering, \\ Politecnico di Milano. 31 Giuseppe Ponzio Street, 20133 Milan, Italy; mesrop.andriasyan@polimi.it \\ 2 Departamento de Expresión Gráfica e Ingeniería en la Edificación, Escuela Técnica Superior de Ingeniería de \\ Edificación, Universidad de Sevilla. 4A Reina Mercedes Avenue, 41012 Seville, Spain; jenieto@us.es \\ 3 Departamento de Prehistoria y Arqueología, Facultad de Geografía e Historia, \\ Universidad de Sevilla. Doña María de Padilla Street, 41004 Seville, Spain; danton@us.es \\ 4 The Creative and Virtual Technologies Research Laboratory, School of Architecture, Design and the Built \\ Environment, Nottingham Trent University, 50 Shakespeare Street, Nottingham NG1 4FQ, UK \\ * Correspondence: jmoyano@us.es
}

Received: 4 March 2020; Accepted: 25 March 2020; Published: 29 March 2020

\begin{abstract}
Building Information Modelling (BIM) is a globally adapted methodology by government organisations and builders who conceive the integration of the organisation, planning, development and the digital construction model into a single project. In the case of a heritage building, the Historic Building Information Modelling (HBIM) approach is able to cover the comprehensive restoration of the building. In contrast to BIM applied to new buildings, HBIM can address different models which represent either periods of historical interpretation, restoration phases or records of heritage assets over time. Great efforts are currently being made to automatically reconstitute the geometry of cultural heritage elements from data acquisition techniques such as Terrestrial Laser Scanning (TLS) or Structure From Motion (SfM) into BIM (Scan-to-BIM). Hence, this work advances on the parametric modelling from remote sensing point cloud data, which is carried out under the Rhino+Grasshopper-ArchiCAD combination. This workflow enables the automatic conversion of TLS and SFM point cloud data into textured 3D meshes and thus BIM objects to be included in the HBIM project. The accuracy assessment of this workflow yields a standard deviation value of 68.28 pixels, which is lower than other author's precision but suffices for the automatic HBIM of the case study in this research.
\end{abstract}

Keywords: parametric modelling; Scan-to-BIM; cultural heritage; point cloud data

\section{Introduction}

\subsection{General Framework}

In the engineering sector, Building Information Modelling (BIM) is considered both an opportunity and a challenge. BIM entails significant time, economic resources and training of the human team, but it also changes the current hiring processes in the development and achievement of engineering and architectural projects. This effort is rewarded with the amount of skills and results that come from applying the BIM technology. Nevertheless, in the field of historic buildings, the use of BIM is limited because of the particularities and characteristics of the heritage, but its presence in the scientific literature is improving. The Heritage or Historic Building Information Modelling (HBIM) approach, which addresses a comprehensive and interdisciplinary management model in the field of heritage, combines 
aspects of geometric variables in a digital environment from 3D models to alphanumeric variables with the incorporation of knowledge and metadata of the object. The scientific literature gathers efforts to achieve the effective application of BIM technologies to heritage [1-5]. The HBIM enables the digital reconstitution of heritage assets $[6,7]$ by considering their actual geometrical alterations $[8,9]$. In addition, diverse simulations can be performed on these models, such as structural behaviour assessment [6,10-12], sustainability [13,14], restoration decision criteria [3], Scan-to-BIM [5-18], safety at work [2], among others; that is, multitude fields of knowledge and implementation environments use these technologies. In this regard, however, Bassier et al. [19] highlighted the difficulty in exchanging data between diverse software and BIM platforms due to compatibility issues, especially with structural behaviour assessment applications.

The HBIM has reached public and private institutions, as well as end-users and professionals in the fields of heritage and construction. This implies the need for guidance and standards in BIM for heritage, which led Historic England [20] and BuildingSmart [21] to publish their BIM manuals. The creation of 3D digital models in the BIM environment is one of the most important parts of this process. Commercial products in architecture started in the late 1980s, e.g., Nemetschek Allplan $®$ [22] and Graphisoft ArchiCAD® [23], the latter being funded by Gábor Bojár and István Gábor Tari in Budapest, Hungary, in 1982 to develop 3D modelling software and compete with AutoCAD® [24]. One of the greatest achievements of BIM software is the integration of a programming environment under the Geometric Description Language (GDL) [25] that allows the creation of parametric objects [26]. These parametric objects allow the creation of 3D geometries such as walls, slabs, floors, columns and stairs, but they are not adaptable to the morphological irregularities sometimes existing in walls and columns of historical buildings.

In contrast, the creation of parametric objects not included in BIM libraries generally require significant time to be modelled or are included in the catalogues of distribution companies. In any case, the issue of not representing the geometrical transformations of historic building components over time prevails. Consequently, great efforts are and must be made in order to reproduce the geometric singularity of the built heritage. To do this, remote sensing point cloud data acquisition techniques such as Terrestrial Laser Scanning (TLS) and Structure From Motion (SFM) or photogrammetry become essential to represent the heritage geometries into BIM. In the scientific literature, this is called the Scan-to-BIM method or process. Multiple scientific works [27-29] develop HBIM projects from point cloud data, but do not fully represent the geometrical alterations of the assets [30-33]. The reason for this is that certain BIM platforms, e.g., ArchiCAD®or Autodesk Revit $₫ ~[34]$, enable the insertion of 2D drawings in PDF format. There are other works that addressed mesh or point cloud conversion algorithms to improve 3D elements in newly constructed buildings [35-38] and heritage buildings $[8,9,27,39]$. Nieto-Julián et al. [5] produced parametric objects with geometrical alterations and further information under the HBIM approach. In this regard, a current debate is the data storage into the HBIM project, such as texture, coating materials, thermal images, structural and conservation information, among others [40]. These data are or should be an essential part of the HBIM, but geometry modelling is certainly an important stage [41].

In view of the above, despite the aforementioned existing incompatibilities between diverse software, there is a need for automating the conversion of point cloud data into BIM. In this sense, although analogous applications could be used for the research aim, this paper explores the potential of the rather recent Rhino+Grasshopper-ArchiCAD combination to present a novel workflow to automatically produce and transfer 3D geometries and their attributes from TLS or SFM point clouds with controllable density to BIM entities with embedded information of the assets. This allows heritage conservation professionals and users without specific knowledge of remote sensing data and 3D/BIM modelling to implement the workflow for heritage.

This paper is structured as follows: once the research problem and the aim are described, related works in the topic are presented. Next, the methodology comprises the definition of the case study; the algorithm-based workflow and other existing algorithms; the improvement of the algorithm for 
building components edges; the validation of the methodology via accuracy assessment, the interface features and the texture generation. The workflow implementation within the BIM environment is then described. Finally, the results are discussed, and the conclusions and future work are presented.

\subsection{Related Work}

Optimising BIM using parametric tools is an issue addressed in the scientific literature. Khaja et al. [42] used parametric tools such as Dynamo [43], an integrated Visual Programming tool from Revit, to demonstrate its potential for automatic population in BIM models. In this line, Rahmani et al. [44] assessed the environmental aspects of the models. ("Data Acquisition and Visualization for IEQ Assessment: A case study of daylight field measurement - White Rose Research Online") worked on statistical simulation on indoor environmental quality, and Rahmani et al. [44] addressed a performance optimisation scenario based on BIM called 'BPOpt' (BIM-based performance optimization).

Most scientific papers on HBIM from point cloud data build these models through manual processes, as in the case study of the Church of Santa Maria at Portonovo (Ancona, Italy) [27]. Here, the objects do not represent the morphological properties from the point clouds; they are created with existing parametric models, but this approach is already described by Murphy et al. [28]. This is also the case of the work by Bassier et al. [29], who reconstructed the portico of the Saint-Jacobs Church (Leuven, Belgium) from an ideal model — without morphological variations-using 3D meshes for later finite element analysis (Finite Element Method, FEM [45]). Barazzetti et al. [46] worked in this line in Castel Masegra in Sondrio, Italy. Sztwiertnia et al. [40] created the HBIM project of the Wang Stave Church in Karpacz, Poland, and identified the difficulty of creating geometric shapes from point cloud data. Progress on adapting complex shapes to parametric elements is respectively made by Antón et al. [8], and Nieto, Antón and Moyano [5]. The former authors converted the point cloud data into as-built 3D solid objects as IFC entities to become part of the HBIM project, which enables the accurate analysis of the heritage city [9] by considering the geometrical alterations of the assets. The latter [5] used Boolean operations within the ArchiCADßBIM platform to implement and manage structural deformations on walls. Therefore, this paper advances on the problem of representing diverse aspects such as structural deformations in the parametric objects, materials through textures, process changes in construction techniques and deformations over the course of time.

Procedures to create 3D parametric objects from point clouds should be mentioned. Barazzetti et al. [47] considered a semi-automatic approach, as it required successive steps to reach editable parametric objects starting from non-uniform rational B-splines (NURBS) and converted into solids. Recent work [48] developed a new workflow for mesh modelling towards HBIM, for which Autodesk Revit (BIM) and Dynamo are used to explore new HBIM features. However, several studies [49,50] implement these tools for specific objects, but not for building construction units. Finally, the work by Tommasi et al. [51] brings together diverse software in the market for reverse engineering in BIM applied to historical elements, whereas Pocobelli et al. [52] integrated organised moisture data into spreadsheets and associated it with parametric objects development through Dynamo.

In addition, there are different reconstruction methods in the scientific literature [53-61], most of which use the Delaunay triangulation [54]. Surface reconstruction is the process of rebuilding geometry from the scanned point cloud. Ideally, the reconstructed surface mesh should have all the mesh faces matching the initial geometry from which the scan was taken.

In this paper, in order to create a new workflow to transfer point cloud data into the BIM environment, a pseudo point cloud structure with controllable density is created from the combination of Rhinoceros [62], Grasshopper [63] - a visual programming language for Rhinoceros—and ArchiCAD. The TLS and SFM data are then converted into textured 3D meshes. The important step is to avoid workflows with complementary software such as Cloudcompare [64], MeshLab [65] or Geomagic [66]. In this workflow, different algorithms are tested for meshing and automatic texture mapping onto the parametric objects. The process consists of converting the numerical model (point cloud) into 
'Morph' elements (for walls and vertical surfaces) and meshes (for floors or horizontal surfaces). Next, these 3D objects are automatically transformed into BIM parametric objects (GSM file format), thus inheriting their dimensional and texture properties. In addition, the accuracy and quality of the model's parameters are evaluated to verify their consistency with an appropriate scale.

Regarding BIM operability with TLS or SFM data, the latest versions of Graphisoft ArchiCAD (R [23] and Autodesk Revit [34] allow to import these point clouds in TXT or XYZ file formats. This enables the BIM creation by fitting the morphological alterations under diverse modelling approaches. However, this paper advances on the automatic conversion of point cloud data into a parametric model by defining shapes through mathematical functions [51] under the Rhino+Grasshopper-ArchiCAD software combination. This workflow interconnects algorithms capable of modelling 3D objects so that the latter can be interoperable, which contributes to scientific knowledge in this field.

\subsection{Case Study: The Main Patio Of The Casa De Pilatos}

This research is based on a case study selected for its characteristics: a complex morphology and existing deformations in walls, columns and ledges, visible to the naked eye. This, together with its two-level porticated structure, makes the Casa de Pilatos suitable as a case study for the aim of this research. The Casa de Pilatos is the former Palace of the Adelantados of Andalusia, in the historic centre of Seville, Spain (Figure 1). The building consists of spaces arranged and transformed over time, among which the main patio stands out. The combination of Mudejar, Gothic and Renaissance styles reveals the architectural richness of this space. Additionally, the patio has overcome diverse modifications due to the expansion needs as a Hispanic-Muslim playground [67]. As mentioned above, the existing pathologies are tilt in walls and columns and deflection in ledges, mainly due to the natural subsidence over time.

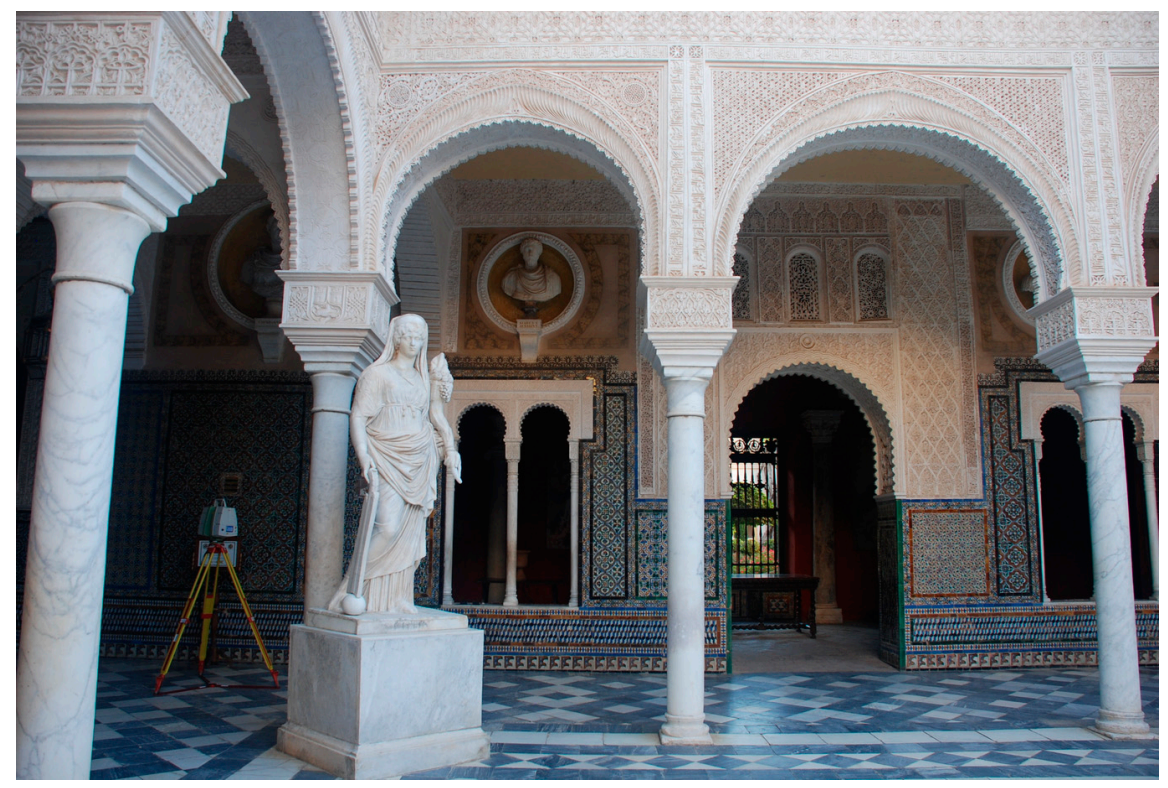

Figure 1. View of the main patio of Casa de Pilatos.

\section{Methodology}

\subsection{The Issue of the Scan-to-HBIM Approach}

As mentioned above, BIM platforms allow to import point cloud data directly, so there is no need

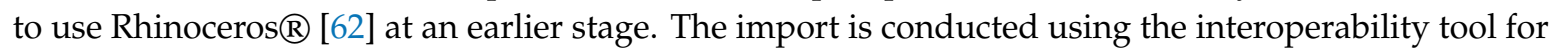
files with topographic coordinates, and then converting the point clouds into mesh objects. These text files must consist of rows of data containing three numerical entries ( $\mathrm{X}, \mathrm{Y}$ and $\mathrm{Z}$ coordinates). Next, the user has to create and align the historic building components referring to the point cloud. Only 
by using the floor/slab tool is the geometry automatically adapted into mesh-like parametric objects, leaving the option to modify the $\mathrm{Z}$ coordinate. In contrast, this procedure is only possible using the wall tool if the point cloud is inserted in the model without any transformation. In this way, the user is able to identify existing deformations, but these are not implicit in the parametric 3D model. In addition, the mentioned parametric objects are included in BIM libraries as standard objects. In order to solve this issue, this paper addresses the automatic creation of parametric objects (as mesh, morph and library objects) from point cloud data under the combination of Rhinoceros, Grasshopper and ArchiCAD. The result is editable mesh parametric objects able to contain metadata and an identification label (ID). Concerning the morph objects, these elements have no geometric limits and are created so that the import of special shapes from other programmes is avoided.

\subsection{Data Collection}

The emergence of new digital technologies has revolutionised the documentation of architectural and cultural heritage. Their origin is the field of reverse engineering given the need to monitor serial manufacturing processes, thus controlling the dimensional quality of the product [68]. From the outset, the digital technology entailed a high economic cost, but the emergence of low-cost software made accurate techniques both affordable and suitable for creating geometrical heritage models.

In this research, diverse surveying methods were used to collect the data, such as classic surveying techniques-laser meter and flexometer to measure interior walls thicknesses-and TLS for the patio. The range and the accuracy of TLS make it ideal for measuring historic buildings [69]. Consequently, this technology was used in this research to carry out the two-stage 3D survey: i) the patio, where three stations (scanner positions) were set to create the XYZ global coordinate system, and ii) the galleries, with four stations in the corners by the galleries. Photographs were also taken using the laser scanner to produce a RGB point cloud (Figure 2). The TLS device was a Leica ScanStation C10, with $120 \mathrm{~m}$ range and a 4-megapixel camera to colourise the cloud. The scan registration (scan alignment) was conducted using Leica Geosystems CycloneßREGISTER 360 software [70]. The error alignment accuracy reached $3 \mathrm{~mm}$ in the patio and $5 \mathrm{~mm}$ in the galleries. The data used for this research was the TLS point cloud in .e57 format.

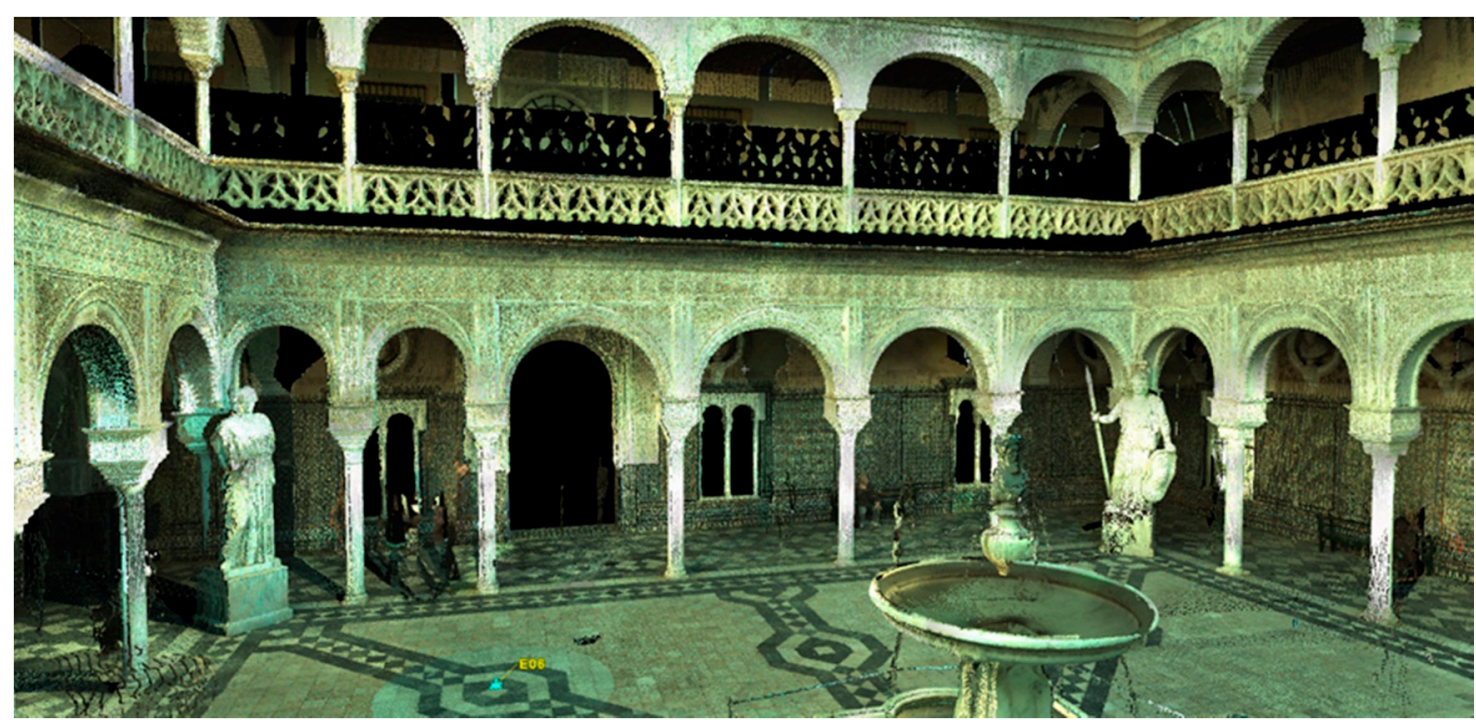

Figure 2. View of the main patio of Casa de Pilatos.

\subsection{Point Cloud Meshing Workflow}

The reconstruction algorithm is designed in such a way that an end user who does not need to know or understand the entire workflow should be able to obtain results from it with a low amount of effort. The workflow is between the traditional Scan-to-BIM method, which requires significant 
manual work, and completely automated AI-oriented methods that take the manual design control role from the architect or any other BIM operator.

This workflow, using Grasshopper and Volvox [71] to process the point cloud and reconstruct surfaces, consists of 3 scripts (Figure 3). The objects generated are later exported to ArchiCAD through the recent ArchiCAD+Grasshopper live connection.

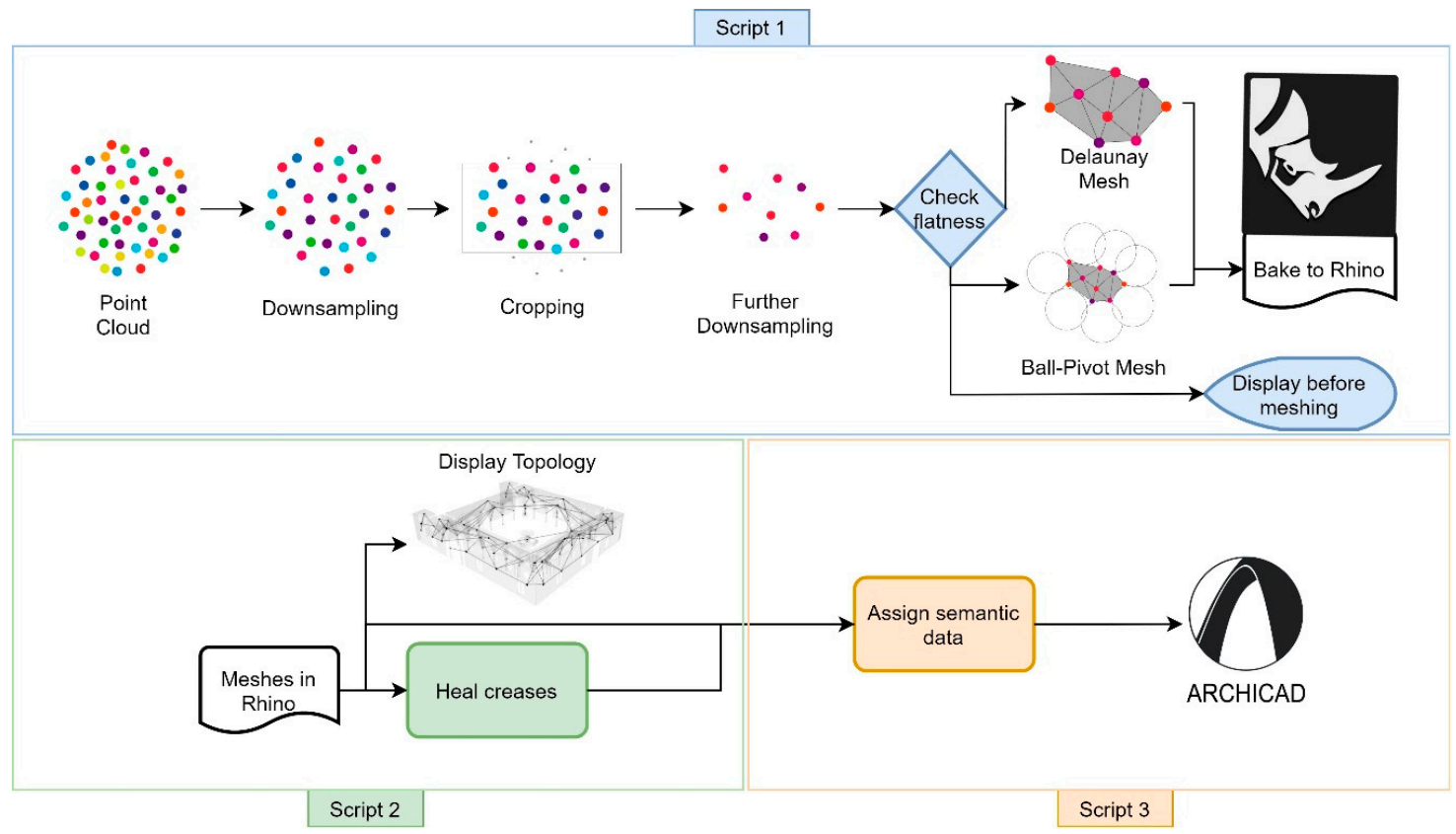

Figure 3. Automatic parametric workflow.

The interface requires user input to use cutting objects to remove segments from the cloud. After the subset is selected, further subselection based on proximity takes place. This operation decreases the complexity of the model and increases homogeneity, which is important for subsequent surface reconstruction.

\subsection{Study Model with an Artificial Point Cloud}

During the development of the algorithm, an artificial point cloud with adjustable parameters was created. Point clouds of a floor sector, two walls and a column were created to replicate scenarios such as the horizontal and vertical planes, and volumetric objects scanned, respectively. A splitting or clipping system is then established; the user creates cutting objects (plane/box/sphere) into the Rhino 3D space and the dynamic pipeline reads them in real-time (Figures 4 and 5).

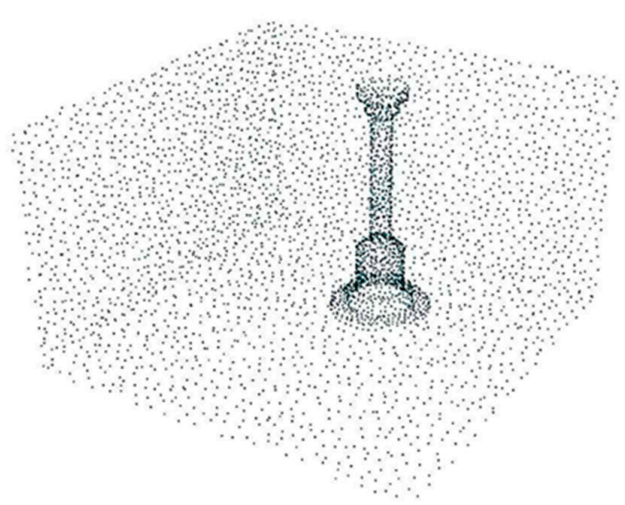

Figure 4. Artificial cloud setup. 


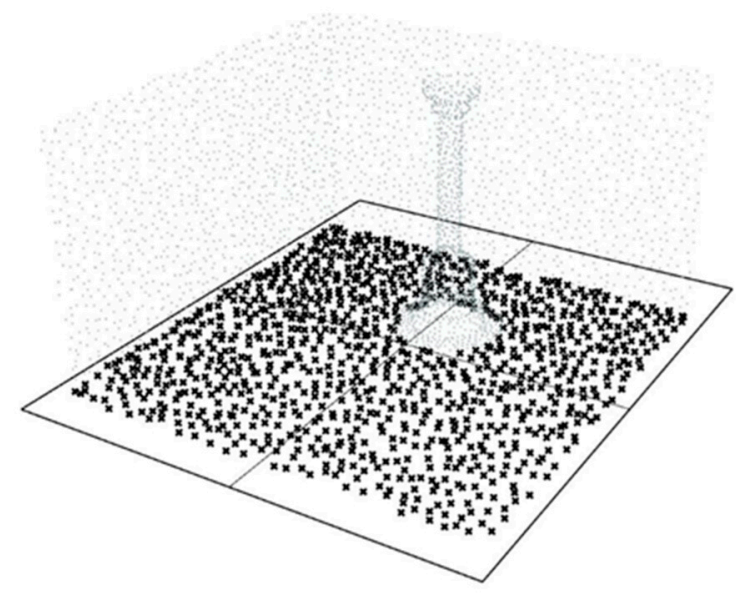

Figure 5. Subset with a clipping plane.

Several cropping objects can be combined in such a way that if the objects intersect each other, the intersection point set is used (Figure 6). Otherwise, the union of separately cropped point subsets is considered.

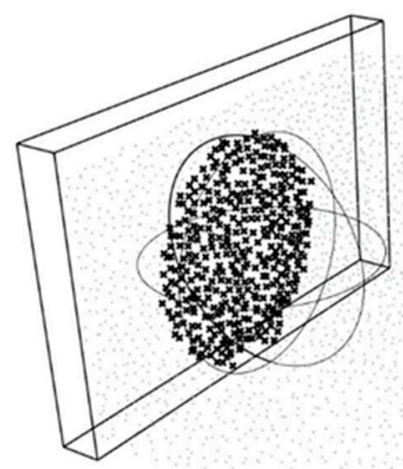

Figure 6. Subset with a sphere and extrusion object.

After the selection is performed, further subsampling based on proximity in RTree [72] is performed to reduce the point quantity.

The algorithm then analyses the shape and planar deviation of the selected cloud subset. If the subset is within the planarity threshold specified by the operator/user/architect, it is then treated as a quasi-planar surface. The fitting plane is calculated and a Delaunay surface reconstruction method is used to produce a mesh object. The fitting planes vertical tilt angle is used to determine whether it is a vertical or horizontal structure (Figure 7). 


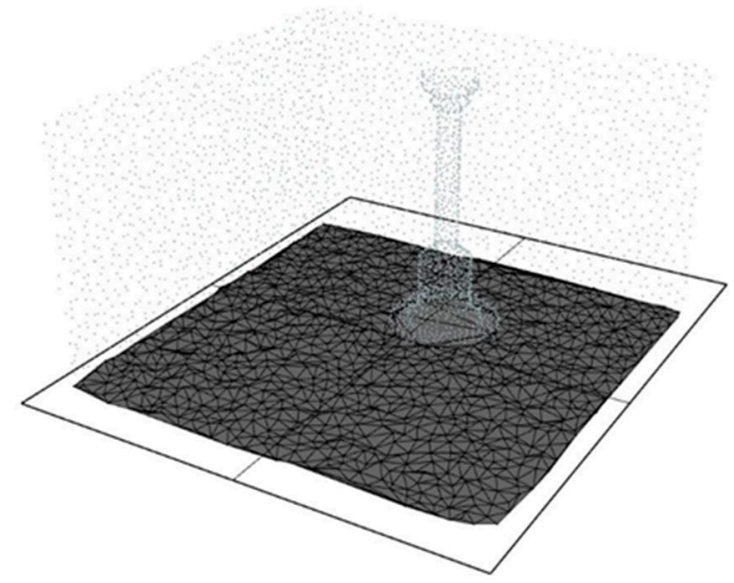

Figure 7. Planar subset surface reconstruction.

On the other hand, in case the selected subset is a volumetric collection of points, a ball-pivot algorithm and several post-processing mesh cleaning procedures are performed to produce 3D shapes (Figure 8).

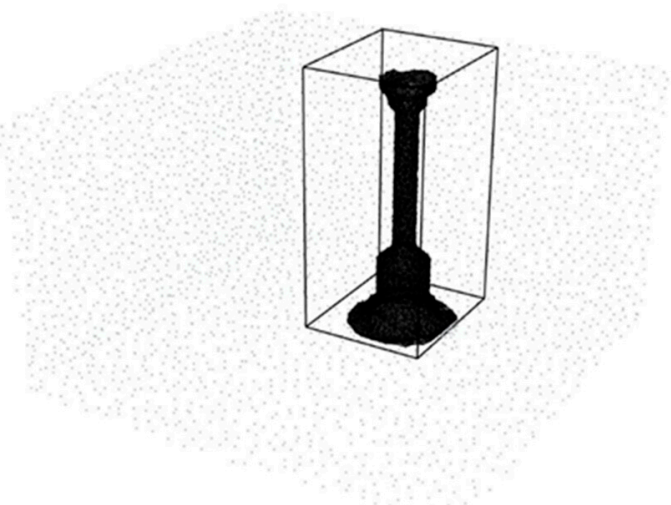

Figure 8. Volumetric subset surface reconstruction.

Post-processing of the mesh includes: removing faces adjacent to non-manifold edges, removing duplicate faces, correcting naked edges, filling the holes (as much as possible) and rebuilding normal vectors.

\subsection{Processing Delaunay Meshes}

As Delaunay meshing always outputs convex geometry, post-processing is performed to cull the extra parts which most of the time are distinguished by having longer edges. The threshold input option is given to the user to control the culling. This is particularly helpful in openings (Figure 9).

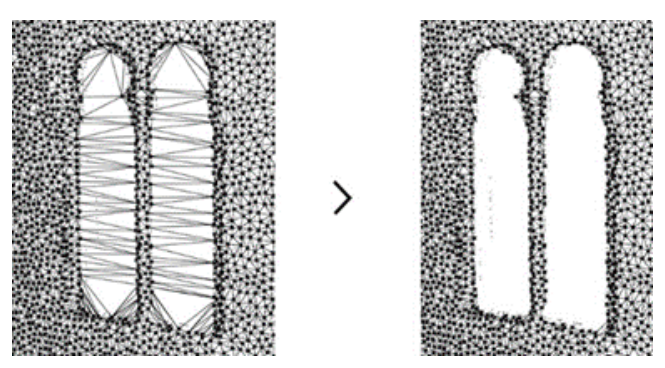

Figure 9. Processed Delaunay mesh of windows. 
Additionally, the model in the galleries will consist of point cloud partitions at the same level representing ceilings in each area. Here, their continuity is only maintained through the walls. If sub selected at a certain level (Figure 10), the meshes can have all the intermediary Delaunay edges deleted in one meshing process, i.e., the user can directly and individually generate the parts.

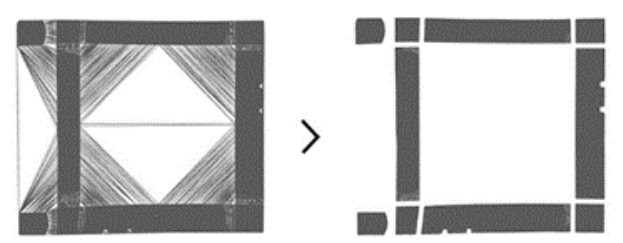

Figure 10. Processed Delaunay mesh of ceilings.

\subsection{Crease Processing}

As the user segments the point cloud using objects (e.g., boxes), it is extremely complicated to obtain the points that are specifically in the intersections of surfaces such as walls or ceilings. This is especially common in heritage buildings, since their structure can be deformed, and the resulting point cloud data samples may be dispersed in the crease regions. In order to overcome this issue, the architect or BIM operator is advised to use overlapping selections. This will create meshes as presented in the upper half of (Figure 11). A separate part of the algorithm is developed to process the crease region between two adjacent meshes so that there are no shared or overlapping faces.
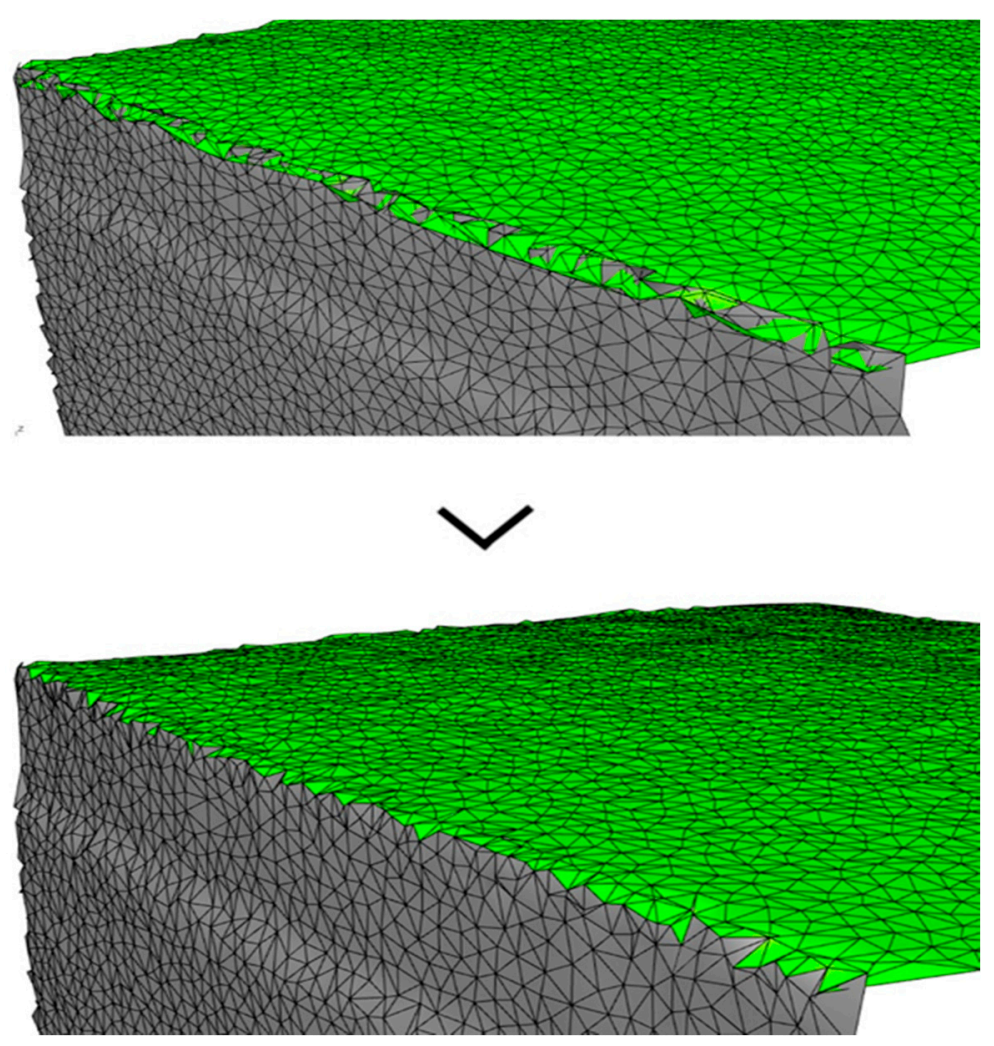

Figure 11. Crease processing between adjacent meshes. 
An oriented bounding box of the crease is created to establish the working space. The faces that fall into this bounding box from both meshes are culled. Based on the points inside the working space a new mesh is generated again using the Delaunay triangulation with the fitted plane. The crease, based on points from the cloud, is then created. The face normals are checked against the average normals of the larger meshes to determine which face belongs to which mesh. In the end, as shown in the lower half of Figure 11, a clean crease between the two meshes is produced.

In order to aid this process, collision events are tested for all potential pairs and a connectivity graph is drawn onto the 3D model (Figure 12). This shows the operator-architect which pairs of meshes should be checked for crease processing.

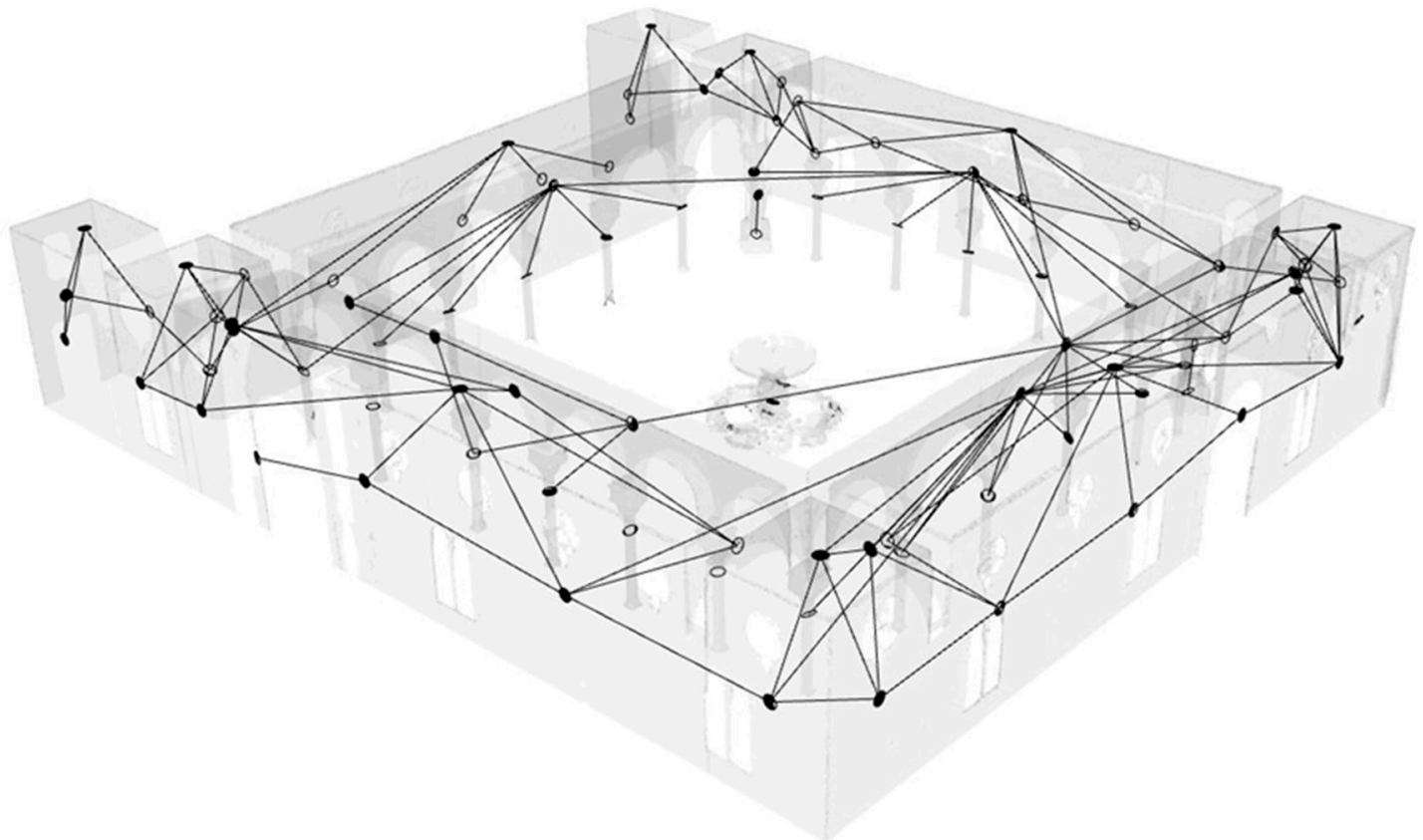

Figure 12. Connectivity graph between meshes.

\subsection{Interface}

Using the Human UI for Grasshopper [73] a custom interface was developed for the architect-operator to make use of the algorithm. The interface (Figure 13) is used for both input values that will determine how the algorithm works and output values that are useful for the user. This includes controls for point cloud subsampling, proximity control for point culling, deviation to treat the selection as planar or volumetric, among others. Some parts of the interface are updated based on the subselection of points. If the subset is determined as planar, an input for Delaunay mesh edge average length multiplier is given to control how much of the long edge faces will be culled. If the subset is determined as volumetric, the input is given for the ball-pivot radius multiplier. Optional smoothing of the mesh may be also performed, which will not increase the mesh face or vertex count. 


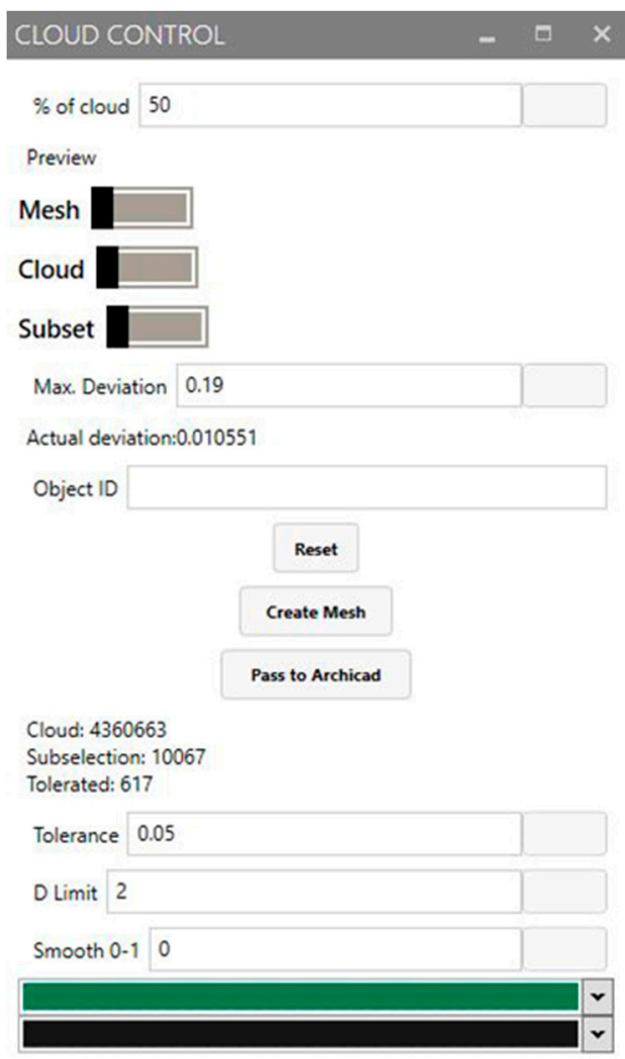

Figure 13. Interface.

\subsection{Automatic Creation Textures}

Point cloud data can also contain information about the colour of the objects scanned. This data, included in the points, is also transferred through the algorithm. However, the ArchiCAD-Grasshopper live connection does not allow the transfer of colour or texture information with morphs so far. This is because texturing in ArchiCAD is not carried out by manual colour coding of individual faces of the morph object but by mapping a texture file onto the object. The latter requires having an actual image file of the texture.

As building components often contain flat-like surfaces (walls, slabs, etc.), a texture image can be used to map them with colour information. The study of the texture creation was conducted on scan data of a wall sector from the Casa de Pilatos Palace. In order to translate the RGB colour information from the point cloud to a texture image file, the following procedures have been implemented: (1) a fitted plane is calculated from the point cloud; (2) the points are projected onto the plane; (3) given that the points are located on the same plane, a bounding rectangle is found to act as the canvas of the future texture image; and (4) the Voronoi [56] division method is used to divide the space into smaller cells, since the point distribution is not regular-diverse point densities exist. Each cell represents an area to be filled with the colour driven by the point which created that cell (Figure 14). 


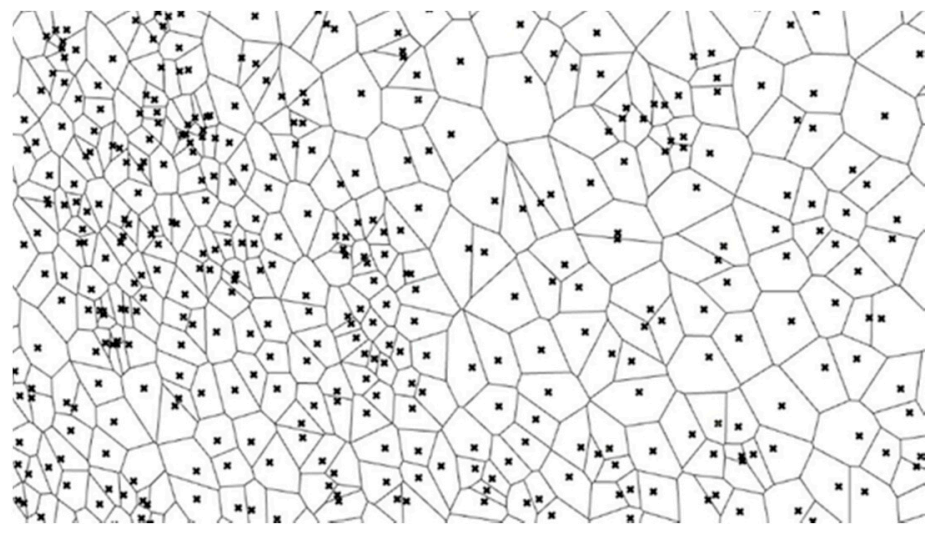

Figure 14. Voronoi division.

\section{Results}

\subsection{Transfer to BIM (ArchiCAD)}

The Grasshopper+ArchiCAD live connection allows the bilateral transfer of geometry between them. Since ArchiCAD works in a BIM environment, it is more rigid when representing non-rectilinear complex geometries. As such the meshes generated with the algorithm contain many faces. There are 3 main object types (tools) in ArchiCAD that can deal with complex forms: 1) the Mesh tool operates the Delaunay meshing algorithm, but it only works in XY plane. This implies that only the flat horizontal parts can be represented using this tool, which may be useful for floors and ceilings; 2) the Morph tool is more flexible and corresponds to the mesh representation in any other usual 3D modelling software, however it is slower than the ArchiCAD Mesh tool; and 3) the Library object tool is also flexible in geometry creation. The library objects are GDL entities containing geometry and texture. Notwithstanding, the colour of the vertexes is not preserved through the transfer of mesh geometry to ArchiCAD. One way of overcoming this issue could be treating each individual mesh face as a separate library part entity, as in the work by Pavlo Menshykh [74], but this approach is not suitable for massive object meshes. The result of the algorithm implementation in BIM is shown in Figure 15.

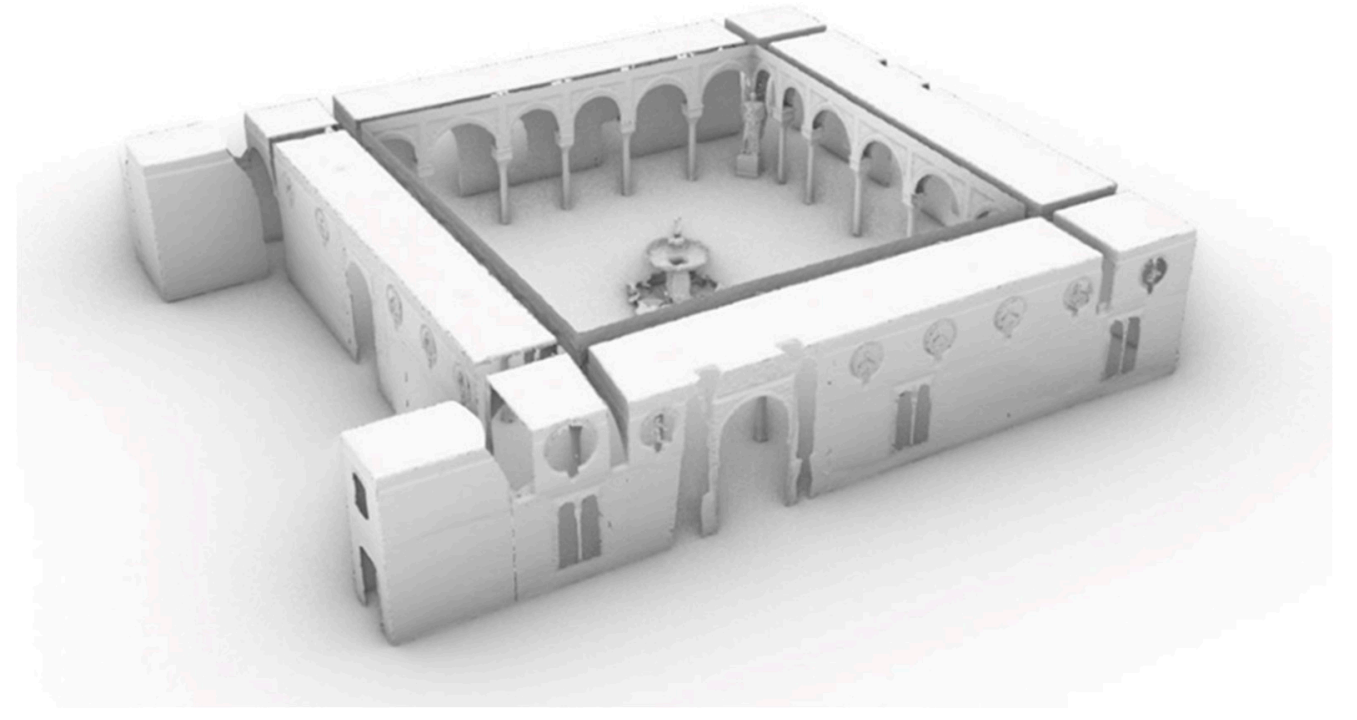

Figure 15. Study model of the Casa de Pilatos patio in ArchiCAD. 


\subsection{Assigning Semantic Data to Objects}

The BIM environment is distinguished among 3D modelling approaches by the ability to assign rich semantic data for each individual object. This is useful in the AEC (Architecture-EngineeringConstruction) industry practices. Each object contains information about its construction element classification, object identifier, renovation cycle type, structural loads, etc. A similar function is available in Rhinoceros environment, where each object is able to include associated user-defined Key+Value attributes. These attributes can be populated and have assigned values to them. The information contained in the Rhinoceros object as a user attribute can be later translated to an ArchiCAD property. In the ArchiCAD environment, however, the semantic data are not simple; some are inherent to the specific object type, others are general and some (after the ArchiCAD 20 update) can be customised by the user in order to represent a certain kind of object associated phenomena. To establish a workflow of the translation of semantic data from Rhinoceros attributes to ArchiCAD data, a script was created to read the custom made ID field of the Rhinoceros object and use it as an input for the object attributes when creating the object (Morph/Library) in ArchiCAD. This approach succeeds to transfer the semantic data; therefore, the other parameters can be set to be transferred in the same manner.

\subsection{Texture Creation}

The aforementioned automatic method enables texture image creation regardless of the point cloud composition. As can be seen in the given example (previous Figures 14, 16 and 17), a portion of the point cloud was subtracted due to the bench in front of the wall. This led to a discontinuity of the cloud particles in that place. Nevertheless, the final image is complete.

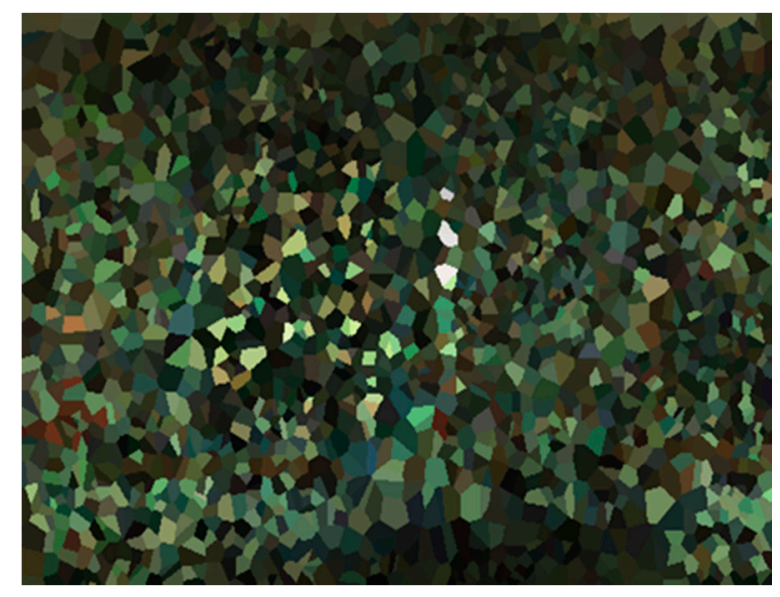

Figure 16. Low-resolution texture creation.

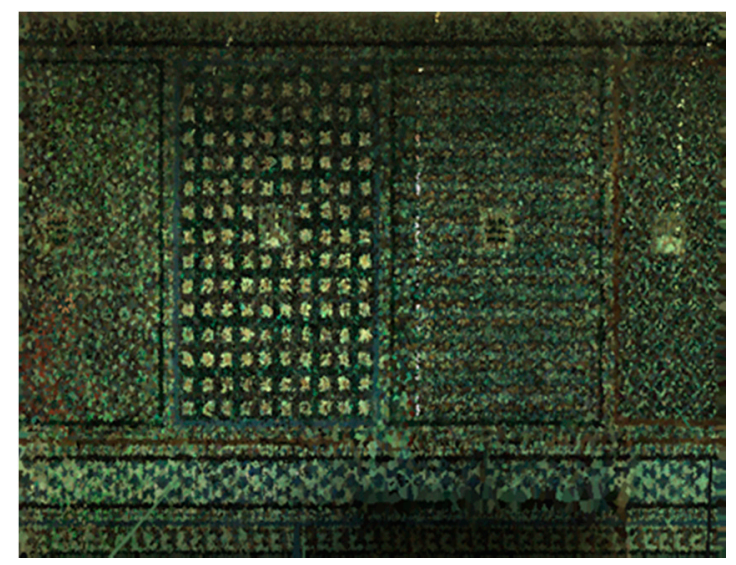

Figure 17. High-resolution texture creation. 
The population size sampled for texture creation can be adjusted to obtain low to high resolution images. However, the resolution here should not be misinterpreted with the pixel resolution of the image. The pixel resolution is controlled separately using an input parameter that stands for the height pixel amount. The length derives from the ratio of the bounding rectangle.

\subsection{Accuracy Evaluation}

Once the meshing algorithm produced the geometry, it was worth assessing the meshing accuracy against the original subsampled point cloud. This was carried out in two sectors of the patio. First, the 3D meshing of a wall sector, whose point cloud had a total of 24,399 points, and its mesh had 3943 polygons and 2033 vertexes. Second, using a sample small mullion column in the patio, with a point cloud consisting of 11,493 points, and a mesh with 1704 faces and 854 points. The geometry comparison was performed as per [8,9], using CloudCompare software to compute the cloud-to-mesh distances (Figures 18 and 19).

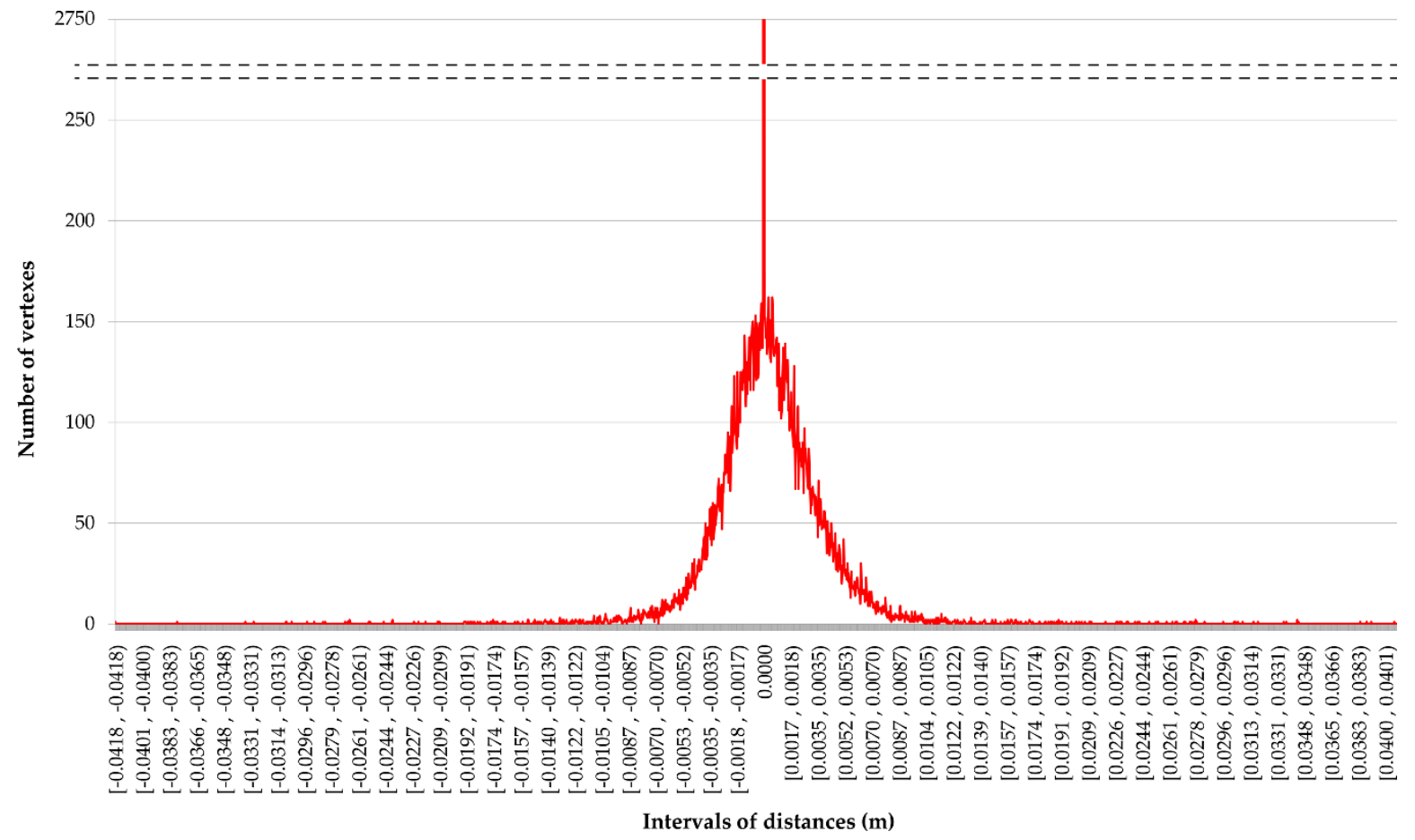

Figure 18. Cloud-to-mesh point deviation in a wall sector.

The scale in both histograms is constant to ease comprehension. The abscissa axis represents the distance intervals between the two 3D objects, and the ordinate axis shows the number of points in each interval. The 'zero' deviation value on the $X$-axis represents the correspondence between the objects compared-3D mesh and point cloud [8,9]. In other words, it is the interval in which the distance between the mesh and the point cloud is null. A total of 2000 distance intervals were created for the calculation; the higher the number of intervals is, the more accurate the number of points in the 'zero' value. The standard deviation $(\sigma)$ was the statistical tool considered to assess the accuracy of the meshing process. In this paper, $\sigma$ was 68.28 points in the wall sector, and 28.13 vertexes in the sample mullion column. 


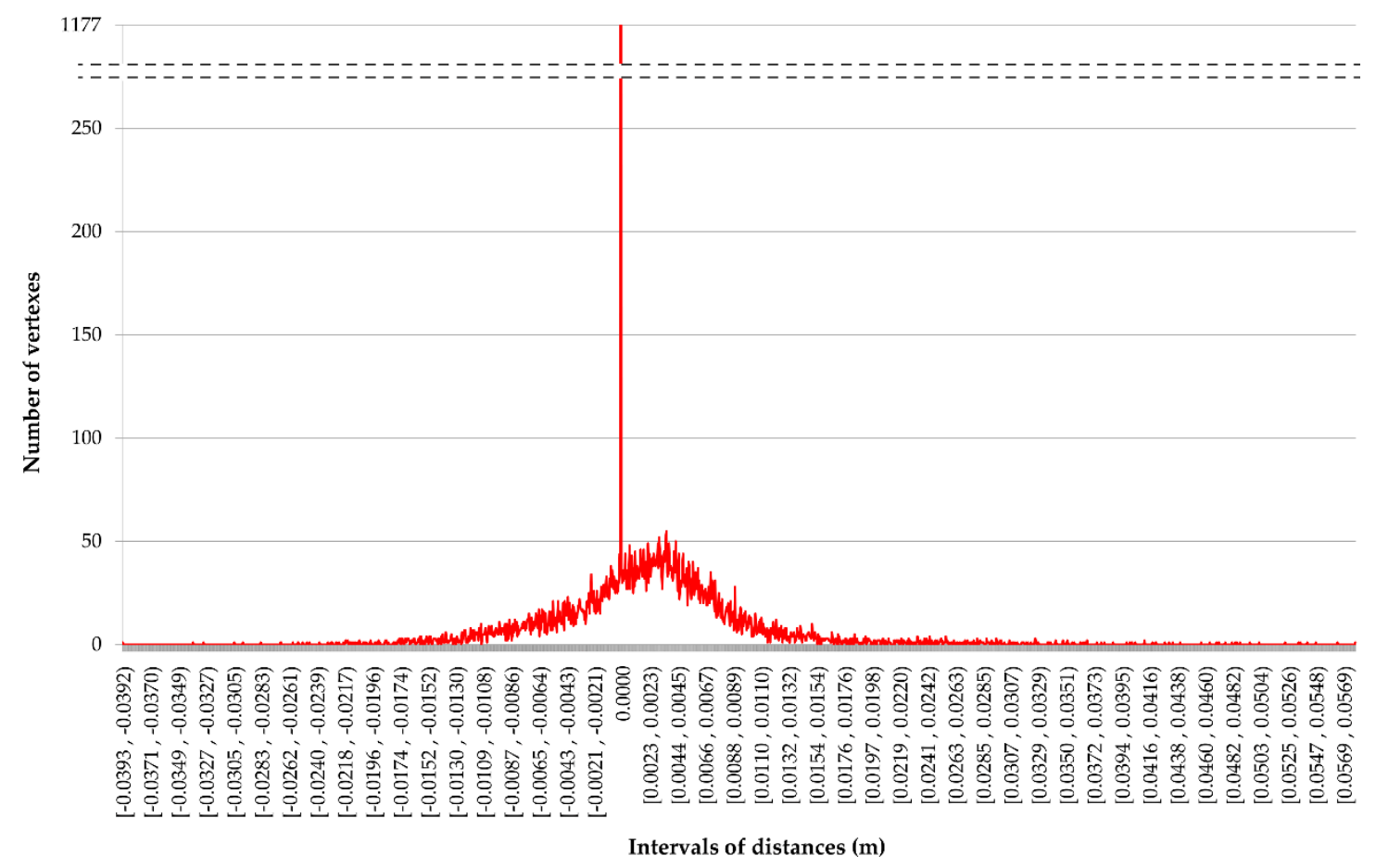

Figure 19. Cloud-to-mesh point deviation in a wall sector.

\section{Discussion of Results}

Firstly, the choice of programmes and algorithm structure should be discussed. Given that 3D modelling applications such as Rhinoceros and ArchiCAD are not intended for point cloud processing, the operations performed in this research may be slower than if performed in specific point cloud processing software. However, the live connection explored in this research (Rhinoceros+Grasshopper-ArchiCAD) allows for linking visual programming to BIM in order to create BIM entities in a complex case study, including flat-like and volumetric building components. Attempts to make large amount of calculations at once may lead to crashes; therefore, in order to achieve a more effective procedure, the algorithm is designed to work on a step-by-step basis through point cloud subselection and processing. As a result, considering the aforementioned software limitations, processing time is reduced, thus revealing the established workflow as an agreement between speed and efficiency.

Secondly, it is worth discussing the different levels of parametrisation. BIM software normally identify their tools and objects as being parametric, however that level of parametrisation is normally bound to those specific objects. For instance, a table can have the drawer sizes parametrically adjusted based on the tabletop dimensions. This is a parametric model but limited to the inherent parameters of the given object. On the other hand, a more global parametrisation suggests that there is a parameter-based connection not only inside one entity but also between different objects. In this regard, the methodology presented here achieves various levels of parametrisation. Examples of object level, multi-object level and global level parametrisations are given below:

- Surface reconstruction, which performs several calculations in order to obtain different parameters for a selected subset of the point cloud.

- The detection of colliding pairs for crease processing described in section 2.6 is a multi-object parametrisation.

- Global parameters: to determine the resolution of point clouds or the BIM objects type choice that the reconstructed mesh will be translated to. 
With a view to avoid confusion with the terms parametric (model) and parametrisation, the BIM entities in this paper (mesh/morph/GDL objects) should not be considered as purely parametric, but as elements which depend on parameters at a certain level.

Thirdly, the performance of the workflow and the user interaction are discussed. The performance depends on the meshing method. Delaunay algorithm in Grasshopper is generally faster and more reliable than the ball-pivot method for point cloud 3D meshing, since the latter was not completely stable in this research. This algorithm caused the programme to crash occasionally, which rarely happened when cropped subsampled clouds contain less than 5000 points. The workflow was tested on an HP Pavilion gaming laptop for performance.

The performance obviously depends on the resolution the user is working with. The higher it is, the smaller portions are advised to be taken for meshing at a time. In this case study, the average collection of points selected for meshing after tolerance culling ranged from 2000 to 10,000 points. In this case, the workflow experienced negligible latency and the calculations took less than 0.5 seconds to compute. The only process that would make the user wait for a short lapse could be the initial point cloud down sampling. On the contrary, transferring the generated meshes into ArchiCAD takes longer time (several seconds for a mesh with 2000 to 5000 points). The more objects that are present in ArchiCAD through the live connection, the longer it will take at each subsequent step. The above led to create a different script for the transfer stage only.

Next, this section is divided into three parts: user recommendations, methods for surface reconstruction and accuracy assessment of the research outcomes.

\subsection{User Recommendations}

The algorithm has been tested in this research; several recommendations can therefore be provided to ease the workflow:

- Every time the geometry is created, it is not necessary to send it to ArchiCAD in order to save the data. The meshes are already saved in Rhinoceros, which means that the transfer to ArchiCAD can be conducted every 5-6 steps or more.

- If working with architectural models, it is highly advisable to position the point cloud in such a way that the least amount of subsampling operations is required. Moreover, it is advisable to orient the cloud to the Cartesian system in Rhinoceros.

- It is easier to control the cropping objects in planar views (top, front, side) rather than in perspective.

- In certain cases, as in this case study, there may be long continuous surfaces such as walls. In the case of heritage objects, the deviation from the fitted plane of those long continuous elements may be extremely high if taken as one piece. In that case, the object may be reconstructed from several pieces that can be determined by the user. This will ensure a better and faster workflow, especially concerning the crease processing algorithm, resulting in seamless and smoother component joints.

\subsection{Different Methods of Source Reconstruction}

It is worth discussing the effectiveness of the aforementioned methods of reconstructing surfaces [59-67]. Certain recently developed algorithms are capable of reconstructing surface efficiently and with high quality of the output mesh. However, there is no implementation of such techniques into the Grasshopper visual scripting environment. Creating Grasshopper components of those techniques is out of the scope of this research; thus, only the methods available at hand were used. Some mesh post-processing operations were developed to test the following set of methods. The algorithm is working only with point positions, so the surface reconstruction can be performed from unoriented point clouds. A point cloud subset was selected to test different methods available for meshing: the fountain in the centre of the patio. 


\subsubsection{Delaunay Meshing}

The Delaunay meshing method is available within Grasshopper and is probably the fastest. It is capable of processing large quantities of points within reasonable time frames. The flat-like parts of the point clouds are reconstructed via Delaunay triangulation with some post-processing.

\subsubsection{Ball-Pivot}

The ball-pivot algorithm [75] is one of such available components used in this paper. It has several advantages and drawbacks. As the radius of the pivot ball remains constant, the accuracy of the yielded model highly depends on the uniformity of the point cloud. If the point cloud has varying densities, which is generally true, the algorithm will fail to connect more distant points and will overrun the closer ones. For this reason, a proximity culling of the points is performed prior to running the ball-pivot algorithm on the point cloud. Although this will not increase the density in the undersampled regions, it will decrease the oversampled region density, thus bringing the overall densities closer to the mean. In order to determine the ball-pivot radius, random subsampling is performed to test the average distance to the nearest 3 neighbouring points. The average of the values is then taken as the base radius. The user is given a numeric control of a multiplier of this value to refine the radius in the end.

\subsubsection{Marching Cubes}

Marching Cubes [76] is another surface reconstruction algorithm available within Grasshopper via the Cocoon developed by David Stasiuk. The resulting reconstructed surfaces were not just thin meshes but more like volumetric envelopes of the objects. In addition, the Marching Cubes algorithm required more parameter inputs from the user, which is far from being automatic.

\subsubsection{Voxelisation}

Volvox includes the voxelisation meshing algorithm. This method was also tested during this research. Although the resulting mesh highly resembled the initial object from which the points were scanned, this method is inapplicable to heritage reconstruction since the final mesh does not represent the scanned points accurately, and may lack crucial data.

Finally, Delaunay meshing was chosen to reconstruct the surfaces in flat regions and ball-pivot was used for the volumetric ones.

\subsection{Meshing Accuracy}

In view of the results of the meshing accuracy evaluation, it is worth noting that, according to Antón et al. [8], high values of the standard deviation account for high accuracy in the 3D meshing process. The values obtained in this research (68.28 and 28.13 vertexes) are lower than the value considered optimal by those authors; i.e., the accuracy is also lower. The extreme distance values between the 3D objects are $0.04 \mathrm{~m}$ and $0.057 \mathrm{~m}$, respectively. However, these values may be outliers, since the starting populated intervals are those below approximately $0.02 \mathrm{~m}$ and $0.04 \mathrm{~m}$, respectively. It is also worth highlighting the symmetry in the data deriving from the accuracy assessment of the wall sector, whereas the case of the mullion column shows a more irregular distribution (Figures 18 and 19). This could indicate a lower 3D meshing accuracy of the algorithm in volumetric components. Consequently, all the above are limitations of this work, but also an opportunity to improve the capabilities of the meshing algorithm in the future. Nevertheless, it should be noted that the aim of the work by the aforementioned authors was to obtain the highest possible accuracy in their 3D heritage models for HBIM by weighing the geometry generation and the mesh triangle amount, which has a direct impact on processing time, computational resources and file size. Thus, the standard deviation calculated in this paper can be accepted for the purpose of modelling the patio of Casa de Pilatos in HBIM. Certainly, the model produced does not include complex decorative details yet, but the 
automatic algorithm is able to represent the overall shape, volume and deformations of the historical building components under the HBIM environment.

\section{Conclusions}

The scientific advance of this work consists of automating and validating the use of BIM in heritage buildings with complex structures. Thus, researchers, architects and BIM operators can identify geometric properties within the platform and represent, evaluate and inventory both structural and pathological deformations of the assets.

In this paper, a new workflow is created to transfer point cloud data into HBIM using the Rhinoceros+Grasshopper-ArchiCAD combination, thus avoiding complementary software such as Cloudcompare, MeshLab or Geomagic. Here, starting from TLS and SFM data, a pseudo point cloud structure with controllable density is created so that the point clouds are converted into textured meshes.

Although according to Facundo et al. [77] Autodesk Revit currently leads the ranking of use in BIM publications in heritage, this software does not solve the problems of surface modelling [52] by itself. In this sense, the Rhino+Grasshopper-ArchiCAD combination demonstrates the possibilities of a new working scenario based on interoperability.

There is a huge potential of parametric modelling, which was described by Lee et al. [78] in 2006. HBIM platforms need algorithmic designs to represent complex structures, and workflows like the one developed in this research can become the next step in this knowledge area. It is in the hands of BIM software developers to introduce these workflows to increase operability as the capabilities of computers to manipulate massive point cloud data improve.

In this work, diverse algorithms such as Marching Cubes, Volvox, Delaunay and ball-pivot have been tested to prove their effectiveness in modelling objects containing geometrical alterations. This is an experimental work to achieve the conversion of TLS or SFM point cloud data into HBIM, thus constituting semantically enriched parametric objects. The 3D meshing accuracy assessment of the algorithm reveals its suitability to represent the overall features and geometrical alterations of the elements modelled.

As mentioned above, not many surface reconstruction algorithms are available at hand in graphical algorithm editors by the time this work was conducted. In the case of the advent of better surface reconstruction tools, the workflow may adopt those new methods for better performance. The ArchiCAD-Grasshopper live connection itself is a relatively new development; further functionalities are therefore expected to be developed in the near future, which will improve the proposed workflow. This may include the possibility of transferring textures directly into the objects, saving generated objects in ArchiCAD in a dynamic manner, among others. This workflow will be used in future case studies and more refinement will be carried out to improve the algorithmic performance.

Author Contributions: Conceptualisation, J.M.; methodology, M.A. and J.E.N.-J.; software, M.A., J.E.N.-J. and D.A.; validation, D.A. and J.E.N.-J.; formal analysis, D.A.; investigation, J.M., M.A. and D.A.; resources, D.A.; data curation, J.M. and D.A.; writing—original draft preparation, J.M., D.A. and M.A.; writing—review and editing, J.M and D.A.; visualisation, M.A., D.A. and J.E.N.-J.; supervision, J.M.; project administration, J.M. and J.E.N.-J; funding acquisition, D.A. and J.M. All authors have read and agreed to the published version of the manuscript.

Funding: This research was funded by: 1) Universidad de Sevilla through VI Plan Propio de Investigación y Transferencia (VIPPIT) grant number CONV-822 and PP2018-10628; and 2) Ministerio de Economía y Competitividad (Spain) through Plan Estatal 2013-2016 Excelencia - Proyectos I+D, project reference HAR2017-83474-P.

Acknowledgments: Thanks to the Administration of Casa de Pilatos for providing access to the building.

Conflicts of Interest: The authors declare no conflict of interest. The funders had no role in the design of the study; in the collection, analyses, or interpretation of data; in the writing of the manuscript, or in the decision to publish the results. 


\section{References}

1. Pavlovskis, M.; Migilinskas, D.; Antucheviciene, J. Implementing BIM for industrial and heritage building conversion. In Proceedings of the 17th International Colloquium Sustainable Decisions in Built Environment, Vilnius, Lithuania, 15 May 2019.

2. Biagini, C.; Capone, P.; Donato, V.; Facchini, N. Towards the BIM implementation for historical building restoration sites. Autom. Constr 2016, 71, 74-86. [CrossRef]

3. Bienvenido-Huertas, D.; Nieto-Julián, J.E.; Moyano, J.J.; Macías-Bernal, J.M.; Castro, J. Implementing Artificial Intelligence in H-BIM Using the J48 Algorithm to Manage Historic Buildings. Int. J. Archit. Herit 2019, 1-13. [CrossRef]

4. Osello, A.; Lucibello, G.; Morgagni, F. HBIM and virtual tools: A new chance to preserve architectural heritage. Buildings 2018, 8, 12. [CrossRef]

5. Nieto-Julián, J.E.; Antón, D.; Moyano, J.J. Implementation and Management of Structural Deformations into Historic Building Information Models. Int. J. Archit. Herit. 2019, 0, 1-14. [CrossRef]

6. Bruno, S.; De Fino, M.; Fatiguso, F. Historic Building Information Modelling: performance assessment for diagnosis-aided information modelling and management. Autom. Constr. 2018, 86, 256-276. [CrossRef]

7. Bacci, G.; Bertolini, F.; Bevilacqua, M.G.; Caroti, G.; Martínez-Espejo Zaragoza, I.; Martino, M.; Piemonte, A. Hbim methodologies for the architectural restoration. the case of the ex-church of san quirico all'olivo in lucca, tuscany. Int. Arch. Photogramm. Remote Sens. Spat. Inf. Sci 2019, W11-2/W11, 121-126. [CrossRef]

8. Antón, D.; Medjdoub, B.; Shrahily, R.; Moyano, J. Accuracy evaluation of the semi-automatic 3D modeling for historical building information models. Int. J. Archit. Herit. 2018, 12, 790-805. [CrossRef]

9. Antón, D.; Pineda, P.; Medjdoub, B.; Iranzo, A. As-built 3D heritage city modelling to support numerical structural analysis: Application to the assessment of an archaeological remain. Remote Sens. 2019, 11, 1276. [CrossRef]

10. Oreni, D.; Brumana, R.; Della Torre, S.; Banfi, F.; Barazzetti, L.; Previtali, M. Survey turned into HBIM: the restoration and the work involved concerning the Basilica di Collemaggio after the earthquake (L'Aquila). Int. Arch. Photogramm Remote Sens. Spat. Inf. Sci. 2014, 2-5; 267-273. [CrossRef]

11. Barazzetti, L. Parametric as-built model generation of complex shapes from point clouds. Adv. Eng. Informatics 2016, 30, 298-311. [CrossRef]

12. Dore, C.; Murphy, M.; McCarthy, S.; Brechin, F.; Casidy, C.; Dirix, E. Structural simulations and conservation analysis-historic building information model (HBIM). Int. Arch. Photogramm Remote Sens. Spat. Inf. Sci. 2015, XL-5/W4, 351-357. [CrossRef]

13. Gigliarelli, E.; Calcerano, F.; Cessari, L. Heritage Bim, Numerical Simulation and Decision Support Systems: An Integrated Approach for Historical Buildings Retrofit. Energy Procedia 2017, 133, 135-144. [CrossRef]

14. Jordan-Palomar, I.; Tzortzopoulos, P.; García-Valldecabres, J.; Pellicer, E. Protocol to manage heritage-building interventions using heritage building information modelling (HBIM). Sustainability 2018, 10, 908. [CrossRef]

15. Stanga, C.; Spinelli, C.; Brumana, R.; Oreni, D.; Valente, R.; Banfi, F. A N-D virtual notebook about the basilica of s. Ambrogio in milan: Information modeling for the communication of historical phases subtraction process. Int. Arch. Photogramm Remote Sens. Spat. Inf. Sci. 2017, XLII-W5, 653-660. [CrossRef]

16. Yilmaz, H.M.; Yakar, M.; Gulec, S.A.; Dulgerler, O.N. Importance of digital close-range photogrammetry in documentation of cultural heritage. J. Cult. Herit. 2007, 8, 428-433. [CrossRef]

17. Bagnolo, V.; Argiolas, R.; Cuccu, A. HBIM for archaeological sites: from SFM based survey to algorithmic modeling. Int. Arch. Photogramm Remote Sens. Spat. Inf. Sci. 2019, XLII-2, 57-63. [CrossRef]

18. Banfi, F. The integration of a scan-To-hbim process in bim application: The development of an add-in to guide users in autodesk revit. Int. Arch. Photogramm Remote Sens. Spat. Inf. Sci. 2019, XLII-2/W11, 141-148. [CrossRef]

19. Bassier, M.; Hadjidemetriou, G.; Vergauwen, M. Implementation of Scan-to-BIM and FEM for the Documentation and Analysis of Heritage Timber Roof Structures. Digit. Herit. Prog. Cult. Herit. Doc. Preserv. Prot. 2016, 1, 79-90.

20. Historic England. BIM for Heritage: Developing a Historic Building Information Model. Available online: https:/historicengland.org.uk/images-books/publications/bim-for-heritage/ (accessed on 17 January 2020). 
21. Fernández, A.A.; Soria, E.; Agustín, L.; Alberto, J.; Adrián, A.; Ereño, B.; Salvador, E.; Jordán, I.; Nieto, E.; Moyano, J.J.; et al. BIM Aplicado al Patrimonio Cultural Coordinador del Proyecto Coordinadores de los Grupos de Trabajo. Available online: https://www.researchgate.net/profile/Juan_Nieto10/ publication/330183791_BIM_aplicado_al_Patrimonio_Cultural_Documento_14_Guia_de_usuarios_ BIM_Building_SMART_Spain_Chapter/links/5c328768299bf12be3b3ed0d/BIM-aplicado-al-PatrimonioCultural-Documento-14-Guia (accessed on 7 January 2020).

22. Nemetschek Allplan-CAD BIM Software-ALLPLAN Systems España S. Available online: https://www. allplan.com/es/ (accessed on 11 December 2019).

23. Graphisoft ArchiCAD 2019. Available online: https://www.graphisoft.com/archicad/ (accessed on 6 August 2019).

24. Martens, B. ArchiCAD: Best Practice: the Virtual Building TM Revealed. Available online: https://www. semanticscholar.org/topic/Geometric-Description-Language/2774212 (accessed on 4 March 2020).

25. ARCHICAD Geometric Description Language. Available online: https://www.semanticscholar.org/topic/ Geometric-Description-Language/2774212 (accessed on 4 March 2020).

26. Merchán, P.; Salamanca, S.; Merchán, M.J.; Pérez, E.; Moreno, D. PASADO, PRESENTE Y FUTURO DE LOS HBIM (HERITAGE/HISTORIC BUILDING INFORMATION MODELS). In Proceedings of the XXXIX Jornadas de Automática, Badajoz, Spain, 5-7 September 2018.

27. Quattrini, R.; Malinverni, E.S.; Clini, P.; Nespeca, R.; Orlietti, E. From tls to hbim. high quality semantically-aware 3d modeling of complex architecture. Int. Arch. Photogramm Remote Sens. Spat. Inf. Sci. 2015, XL-5/W4, 367-374. [CrossRef]

28. Murphy, M.; Pavia, S.; Mc Govern, E. Correlation of laser-scan surveys of irish classical architecture with historic documentation from architectural pattern books. In Architecture and Mathematics from Antiquity to the Future: Volume II: The 1500s to the Future; Springer: Basel, Switzerland, 2015.

29. Bassier, M.; Vergauwen, M.; Van Genechten, B. Automated classification of heritage buildings for as-built bim using machine learning techniques. Isprs. Ann. Photogramm. Remote Sens. Spat. Inf. Sci 2017, IV-2/W2, 25-30. [CrossRef]

30. Acierno, M.; Cursi, S.; Simeone, D.; Fiorani, D. Architectural heritage knowledge modelling: An ontology-based framework for conservation process. J. Cult. Herit. 2017, 24, 124-133. [CrossRef]

31. Baik, A. From point cloud to Jeddah Heritage BIM Nasif Historical House - case study. Digit. Appl. Archaeol. Cult. Herit. 2017, 4, 1-18. [CrossRef]

32. López, F.J.; Lerones, P.M.; Llamas, J.; Gómez-Garcia-Bermejo, J.; Zalama, E. Linking HBIM graphical and semantic information through the Getty AAT: Practical application to the Castle of Torrelobatón. Iop Conf. Ser.: Mater. Sci. Eng. 2018, 364. [CrossRef]

33. Garagnani, S.; Gaucci, A.; Govi, E. Archaeobim: Dallo scavo al building information modeling di una struttura sepolta. Il caso del tempio tuscanico di uni a marzabotto. Archeol. E Calc. 2016, 27, 251-270.

34. Autodesk. Autodesk Revit BIM Software. Available online: https:/www.autodesk.com/products/revit/ overview (accessed on 13 February 2020).

35. Thomson, C.; Boehm, J. Automatic geometry generation from point clouds for BIM. Remote Sens. 2015, 7, 11753-11775. [CrossRef]

36. Wang, C.; Cho, Y.K.; Kim, C. Automatic BIM component extraction from point clouds of existing buildings for sustainability applications. Autom. Constr. 2015, 56, 1-13. [CrossRef]

37. Maalek, R.; Lichti, D.D.; Ruwanpura, J.Y. Automatic recognition of common structural elements from point clouds for automated progress monitoring and dimensional quality control in reinforced concrete construction. Remote Sens. 2019, 11, 1102. [CrossRef]

38. Díaz-Vilariño, L.; Conde, B.; Lagüela, S.; Lorenzo, H. Automatic detection and segmentation of columns in as-built buildings from point clouds. Remote Sens. 2015, 7, 15651-15667. [CrossRef]

39. Tang, P.; Huber, D.; Akinci, B.; Lipman, R.; Lytle, A. Automatic reconstruction of as-built building information models from laser-scanned point clouds: A review of related techniques. Autom. Constr. 2010, 19, 829-843. [CrossRef]

40. Sztwiertnia, D.; Ochałek, A.; Tama, A.; Lewińska, P. HBIM (heritage Building Information Modell) of the Wang Stave Church in Karpacz - Case Study. Int. J. Archit. Herit. 2019, 1-15. [CrossRef]

41. Quattrini, R.; Pierdicca, R.; Morbidoni, C. Knowledge-based data enrichment for HBIM: Exploring high-quality models using the semantic-web. J. Cult. Herit. 2017, 28, 129-139. [CrossRef] 
42. Khaja, M.; Seo, J.D.; McArthur, J.J. Optimizing BIM Metadata Manipulation Using Parametric Tools. Procedia Engineering 2016, 145, 259-266. [CrossRef]

43. Autodesk Dynamo BIM. Available online: https://dynamobim.org/ (accessed on 4 March 2020).

44. Rahmani Asl, M.; Zarrinmehr, S.; Bergin, M.; Yan, W. BPOpt: A framework for BIM-based performance optimization. Energy Build. 2015, 108, 401-412. [CrossRef]

45. Zienkiewicz O., C.; Taylor, R.L. The Finite Element Method: Solid mechanics; Butterworth-Heinemann: Oxford, UK, 2000.

46. Barazzetti, L.; Banfi, F.; Brumana, R.; Gusmeroli, G.; Previtali, M.; Schiantarelli, G. Cloud-to-BIM-to-FEM: Structural simulation with accurate historic BIM from laser scans. Simul. Model. Pract. Theory 2015, 57, 71-87. [CrossRef]

47. Barazzetti, L.; Banfi, F.; Brumana, R. Historic BIM in the Cloud. In Proceedings of the the Digital Heritage. Progress in Cultural Heritage: Documentation, Preservation, and Protection, Nicosia, Cyprus, 29 October 2016; pp. 104-115.

48. Yang, X.; Lu, Y.-C.; Murtiyoso, A.; Koehl, M.; Grussenmeyer, P. HBIM Modeling from the Surface Mesh and Its Extended Capability of Knowledge Representation. Isprs Int. J. Geo-Inf. 2019, 8, 301. [CrossRef]

49. Lu, Y.C.; Shih, T.Y.; Yen, Y.N. Research on historic bim of built heritage in taiwan \&ndash; a case study of huangxi academy. Isprs-Int. Arch. Photogramm. Remote Sens. Spat. Inf. Sci. 2018, XLII-2, 615-622. [CrossRef]

50. Battini, C.; Vecchiattini, R. Data parametric representation for monitoring of cultural heritage. Appl. Geomat. 2018, 10, 191-204. [CrossRef]

51. Tommasi, C.; Achille, C.; Fassi, F. From point cloud to bim: a modelling challenge in the cultural heritage field. Isprs-Int. Arch. Photogramm. Remote Sens. Spat. Inf. Sci 2016, XLI-B5, 429-436. [CrossRef]

52. Pocobelli, D.P.; Boehm, J.; Bryan, P.; Still, J.; Grau-Bové, J. Building information models for monitoring and simulation data in heritage buildings. Int. Arch. Photogramm, Remote Sens. Spat. Inf. Sci. 2018, XLII-2, 909-916. [CrossRef]

53. Pang, X.; Song, Z.; Lau, R.W.H. An effective quad-dominant meshing method for unorganized point clouds. Graph. Models 2014, 76, 86-102. [CrossRef]

54. Cazals, F.; Giesen, J. Delaunay triangulation based surface reconstruction. In Effective Computational Geometry for Curves and Surfaces 2006, 231-276.

55. Ladicky, L.; Saurer, O.; Jeong, S.; Maninchedda, F.; Pollefeys, M. From Point Clouds to Mesh Using Regression. In Proceedings of the IEEE International Conference on Computer Vision; Venice, Italy, 22-29 October 2017, Institute of Electrical and Electronics Engineers Inc.: Piscataway, NJ, USA, 2017; Volume 2017, pp. 3913-3922.

56. Amenta, N.; Bern, M.; Kamvysselis, M. A New Voronoi-Based Surface Reconstruction Algorithm. In Proceedings of the the 25th Annual Conference on Computer Graphics and Interactive Techniques, SIGGRAPH 1998, Orlando, FL, USA, 19 July-24 1998; Association for Computing Machinery: New York, NY, USA, 1998; pp. 415-422.

57. Brumana, R.; Oreni, D.; Raimondi, A.; Georgopoulos, A.; Bregianni, A. From survey to HBIM for documentation, dissemination and management of built heritage: The case study of St. Maria in Scaria d'Intelvi. In Proceedings of the 2013 Digital Heritage International Congress (DigitalHeritage), Marseille, France, 28 October-1 November 2013; Volume 1, pp. 497-504.

58. Wang, W.; Su, T.; Liu, H.; Li, X.; Jia, Z.; Zhou, L.; Song, Z.; Ding, M. Surface reconstruction from unoriented point clouds by a new triangle selection strategy. Comput. Graph. (Pergamon) 2019, 84, 144-159. [CrossRef]

59. Zhong, S.; Zhong, Z.; Hua, J. Surface reconstruction by parallel and unified particle-based resampling from point clouds. Comput. Aided Geom. Des. 2019, 71, 43-62. [CrossRef]

60. Mineo, C.; Pierce, S.G.; Summan, R. Novel algorithms for 3D surface point cloud boundary detection and edge reconstruction. J. Comput. Des. Eng. 2019, 6, 81-91. [CrossRef]

61. Li, E.; Che, W.; Zhang, X.; Zhang, Y.K.; Xu, B. Direct quad-dominant meshing of point cloud via global parameterization. In Proceedings of the Computers and Graphics (Pergamon), Vancouver, BC, Canada, 5-7 August 2011; Volume 35, pp. 452-460.

62. Robert McNeel \& Associates Rhinoceros. Available online: https://www.rhino3d.com/ (accessed on 27 March 2020).

63. Robert McNeel \& Associates Grasshopper. Available online: https://www.grasshopper3d.com/ (accessed on 4 March 2020). 
64. Daniel Girardeau-Montaut, D. CloudCompare: 3D Point Cloud and Mesh Processing Software. Open Source Project 2016. Available online: https://www.danielgm.net/index.php (accessed on 9 May 2019).

65. Cignoni, P.; Callieri, M.; Corsini, M.; Dellepiane, M.; Ganovelli, F.; Ranzuglia, G. MeshLab: an Open-Source Mesh Processing Tool. In Proceedings of the In Eurographics Italian Chapter Conference, Melbourne, Australia, 7-10 December 2008; Scarano, V., De Chiara, R., Erra, U., Eds.; The Eurographics Association: Salerno, Italy, 2008.

66. Systems, 3D Geomagic Studio. Available online: http://www.3dcadportal.com/geomagic-studio.html (accessed on 4 March 2020).

67. Cañal, V. La Casa de Pilatos. In Proceedings of the Architecture et vie sociale: l'organisation intérieure des grandes demeures à la fin du Moyen Age et à la Renaissance: Actes du colloque tenu à Tours, Paris, France, 6-10 June 1988.

68. M. Santana Quintero Información al Servicio del Mantenimiento Preventivo del Patrimonio Arquitectonico: Conceptos y Práctica. Available online: https://imo.libis.be/primo-explore/fulldisplay? docid=LIRIAS1773968\&context=L\&vid=Lirias\&search_scope=Lirias\&tab=default_tab\&lang=en_US\& fromSitemap=1 (accessed on 23 January 2020).

69. Altuntas, C. Integration of point clouds originated from laser scanner and photogrammetric images for visualization of complex details of historical buildings. Int. Arch. Photogramm Remote Sens. Spat. Inf. Sci. 2015, XL-5/W4, 431-435. [CrossRef]

70. Geosystems, L. Leica Cyclone REGISTER 360-3D Laser Scanning Point Cloud Registration Software; Leica Geosystems AG: Heerbrugg, Switzerland, 2018.

71. Zwierzycki, M.; Evers, H.L.; Tamke, M. Parametric Architectural Design with Point-clouds Volvox. In Proceedings of the In Proceedings of the 34th eCAADe Conference, Oulu, Finland, 22-26 August 2016.

72. Guttman, A. R-trees: A dynamic index structure for spatial searching. In Proceedings of the ACM SIGMOD Record, Boston, MA, USA, 18-21 June 1984; Volume 14, pp. 47-57.

73. Human UI/Food4Rhino. Available online: https://www.food4rhino.com/app/human-ui (accessed on 24 January 2020).

74. Pavlo Menshy (12) Heightmap in ARCHICAD/LinkedIn . Available online: https://www.linkedin.com/pulse/ heightmap-archicad-pavlo-menshykh/ (accessed on 24 January 2020).

75. Bernardini, F.; Mittleman, J.; Rushmeier, H.; Silva, C.; Taubin, G. The ball-pivoting algorithm for surface reconstruction. IEEE Trans. Vis. Comput. Graph. 1999, 5, 349-359. [CrossRef]

76. Lorensen, W.E.; Cline, H.E. Marching cubes: A high resolution 3D surface construction algorithm. In Proceedings of the 14th Annual Conference on Computer Graphics and Interactive Techniques, SIGGRAPH 1987, Anaheim, CA, USA, 27-31 July 1987; pp. 163-169.

77. López, F.; Lerones, P.; Llamas, J.; Gómez-García-Bermejo, J.; Zalama, E. A Review of Heritage Building Information Modeling (H-BIM). Multimodal Technol. Interact. 2018, 2, 21. [CrossRef]

78. Lee, G.; Sacks, R.; Eastman, C.M. Specifying parametric building object behavior (BOB) for a building information modeling system. Autom. Constr. 2006, 15, 758-776. [CrossRef]

(C) 2020 by the authors. Licensee MDPI, Basel, Switzerland. This article is an open access article distributed under the terms and conditions of the Creative Commons Attribution (CC BY) license (http://creativecommons.org/licenses/by/4.0/). 